\title{
Data-Driven Evaluation and Optimization of Agricultural Sustainable Development Capability: A Case Study of Northern Anhui
}

\author{
Muchen Luo ${ }^{1,2}$, Fan Liu ${ }^{2,3, *(1)}$ and Jianqing Chen ${ }^{4}$ \\ 1 School of Management, Suzhou University, Suzhou 234000, China; mcluo@ahszu.edu.cn \\ 2 School of Economics, Anhui University, Hefei 230601, China \\ 3 School of Business, Suzhou University, Suzhou 234000, China \\ 4 Institute of Technology, Huzhou College, Huzhou 313000, China; chenjq@zjhu.edu.cn \\ * Correspondence: fl@ahszu.edu.cn; Tel.: +86-15178219270
}

Citation: Luo, M.; Liu, F.; Chen, J. Data-Driven Evaluation and Optimization of Agricultural Sustainable Development Capability: A Case Study of Northern Anhui. Processes 2021, 9, 2036. https:// doi.org/10.3390/pr9112036

Academic Editors: Jorge Cunha, Paula Varandas Ferreira and Wei Cai

Received: 23 October 2021

Accepted: 12 November 2021

Published: 14 November 2021

Publisher's Note: MDPI stays neutral with regard to jurisdictional claims in published maps and institutional affiliations.

Copyright: (C) 2021 by the authors. Licensee MDPI, Basel, Switzerland. This article is an open access article distributed under the terms and conditions of the Creative Commons Attribution (CC BY) license (https:// creativecommons.org/licenses/by/ $4.0 /)$.

\begin{abstract}
Human survival depends on the sustainable development of agriculture. This study constructs a data-driven evaluation and optimization method of agricultural sustainable development capacity, aiming to better cope with challenges such as environmental pollution and excessive consumption of resources and energy, as well as improve agricultural economic level. Further, an evaluation index system was constructed based on comprehensive consideration of energy and resources utilization, environmental pollution, and agricultural economy. After simplifying and integrating the data, a data envelopment analysis model was constructed to quantitatively evaluate the capability for agricultural sustainable development and its changing trend. Moreover, its influencing factors were analyzed from the perspective of input, which provides accurate countermeasures for improving agricultural sustainable development ability, resource utilization efficiency, and process optimization. This study shows the realization process of the aforementioned method for the agricultural development of six cities in northern Anhui from 2010 to 2019. Our results suggest that the sustainable development ability of northern Anhui is weak, but overall, has a good development trend. Based on our results, some countermeasures were proposed to control production scale reasonably, reduce environmental load, and improve resource efficiency, which provides a reference for policymakers to guide and standardize the development of regional agriculture.
\end{abstract}

Keywords: data driven; agricultural sustainable development capability; economic and environmental index system; resource efficiency; agricultural process optimization

\section{Introduction}

Agriculture economy is the foundation of not only national economy but also human existence. Additionally, the sustainable development of agriculture is the foundation for the sustainable development of the whole society. In recent years, the problem of sustainable development of agriculture has become the primary focus in global discussions. According to the Food Crisis Report released by the World Food Program, the number of people facing food crisis worldwide in 2019 was 135 million. 'Food and Agriculture in 2020' issued by the Food and Agriculture Organization of the United Nations (FAO) points out that 3.2 billion people worldwide will face water shortages in 2020. Most countries are promoting the coordinated development of agricultural production and ecology. The intention is to focus on the development and innovation of digital agriculture [1,2], promote the optimal allocation of agricultural resources [3], accelerate the optimization of agricultural industrial structures [4], improve the efficiency and competitiveness of agricultural production and promote its sustainable development. Nevertheless, the increase in world population [5], shortage of water resources [6,7], and environmental pollution [8,9], are creating new challenges for the sustainable development of world agriculture [10]. Therefore, it is 
necessary to promote a sustainable agricultural model [11], build evaluation indicators based on these challenges, and objectively measure the capacity of regional sustainable agricultural development by using data to optimize its capability.

Agriculture is very important for any country; many scholars have carried out research and discussion on the sustainable development of agriculture. First, the theory of agricultural sustainable development was studied. Research on the theory of agricultural sustainable development is primarily based on Daly's four standards of sustainable development goals [12], environmental Kuznets curves [13,14], emergy theory and analysis methods [15], and other theories. In 1988, the US Congress passed the "Low-input and Sustainable Agriculture (LISA)" program, which is based on improving ecological benefits and protecting the ecological environment, setting diversified agricultural development goals, and increasing the intensity and scope of agricultural subsidies [16]. The "17 sustainable development goals (SDGs) to transform our world" report of the United Nations Department of Economic and Social Affairs highlighted the need for countries to take action to achieve sustainable management and efficient use of natural resources by 2030 [17]. "Sustainable agriculture" is a major change in the course of world agricultural development [18]. Most agriculturalists have reached a consensus that the theoretical study of sustainable agriculture is essential to realize the sustainability of the biosphere and its population growth [19]. Sustainable agricultural development depends on the efficient use of resources and risk management strategies [20]; hence, we need to focus on better use of natural and human resources [21]. Second, the evaluation and measure of sustainable agricultural development were studied. To evaluate the sustainable development ability of agriculture, it is necessary to build an evaluation index system [22]. The evaluation indicators are based on focused investigation and regional differences, and hence, are thoroughly different. Index systems have been constructed using several indicators, including fuel use and agricultural waste [23]; crop growth and soil quality change [24,25]; assets [26]; utilization of water resources [27]; level of farmers' mutual cooperation [28]; regional population, resources, and social economy [29]; and productivity, profitability, and soil health [30]. Furthermore, scholars have explored different methods for evaluating regional capacity for sustainable development of agriculture, including the carbon footprint method of agricultural production [31,32], reference evapotranspiration index [33], direct impact model of agricultural production [34], emergy analysis [35], logarithmic mean divisor index decomposition method [36], and life cycle assessment method [37]. Finally, the optimization and countermeasures of agricultural sustainable development ability were studied. Sustainable development of agriculture is driven by many factors. Many scholars have carried out relevant research and put forward solutions from various angles. For instance, Poveda et al. proposed that crops and other organisms coexist harmoniously [38,39], Lemaire et al. proposed to improve the content of soil chemical elements [40], Ashraf et al. proposed to increase scientific and technological innovation, and improve agricultural production technology [41], Zhou et al. demonstrated that sustainable agricultural development can be achieved by controlling production scale and developing intensive agriculture [42,43], and Wings et al. put forward suggestions to promote sustainable agricultural development from the angle of controlling environmental pollution and reducing environmental load $[44,45]$. Academic circles have provided many directions for countermeasures and suggestions, but the development of agriculture has great regional differences. Hence, it is necessary to put forward countermeasures and suggestions in line with the actual situation, while also considering the regional characteristics.

Although numerous studies have been conducted on the sustainable development ability of regional agriculture, the following deficiencies remain: (1) Numerous factors are involved in agricultural development, including the utilization of cultivated land, agricultural machinery power, and other resources, as well as the relevant indicators of environmental pollution. Establishing a scientific evaluation index system for sustainable development is the theoretical basis for objectively judging the ability for sustainable development of agriculture. (2) The evaluation of agricultural sustainable development 
ability is a complex system, which needs to consider the relationship between input and output. Further, though it should be ensured that the current output meets the demand, it should also be ensured that the output does not hinder future development due to over-exploitation and waste. Therefore, based on the above factors, it is urgent to construct an evaluation method for measuring the ability for sustainable development of agriculture and summarizing the changing trend of the ability for sustainable development. (3) At present, the main research direction of scholars is to investigate whether a certain factor can effectively improve the sustainable development ability of agriculture. However, there are many factors that affect the sustainable development of agriculture. Therefore, it is necessary to construct a data-driven mechanism to improve the sustainable development ability of agriculture, accurately reveal the main factors that affect the sustainable development ability of agriculture, and then put forward effective countermeasures and suggestions for improving the ability for the sustainable development of agriculture.

To address the challenges discussed and fill the existing knowledge gaps, better cope with environmental pollution and excessive consumption of resources and energy, improve the agricultural economy levels, and promote its sustainable development, this study proposed an evaluation and optimization method for regional agricultural sustainable development capacity based on the work by Liu et al. [46,47]. The present study has both theoretical and practical significance. The theoretical significance is as follows: This paper studies the measurement, evaluation, and optimization of the capability for the development of sustainable agriculture from a data-driven perspective. First, the phenomenon of yield growth and income increase at the expense of resources and the environment was elucidated by using the theory of sustainable agricultural developments. The related indicators of agricultural water and electricity utilization, and the related indicators of agricultural pollution, such as livestock manure and agricultural wastewater, were taken as input indicators. Moreover, the agricultural output value and the income of employees representing the living standard were taken as output indicators. Thus, a more scientific and objective comprehensive evaluation system was constructed. Second, an evaluation model of agricultural sustainable development ability was constructed to realize the mutual comparison and quantitative evaluation of the ability for the sustainable development of agriculture; at the same time enabling the evaluation of the change in trend of the ability for sustainable development. Thirdly, a data-driven mechanism for improving the ability for sustainable development of agriculture was constructed, and the main influencing factors of agricultural sustainable development ability were accurately found, providing a decision-making basis for improving agricultural sustainable development ability. The practical significance is as follows: First, this article can help governments and researchers to master the methods for evaluating the ability for agricultural development and changing trends comprehensively, objectively, and quantitatively. Second, through data-driven analysis, identify the key factors affecting the ability for sustainable development, and identify directions for improving agricultural development and enhancing agricultural competitiveness in the future.

The next section introduces the methods used, including data collection, mathematical modeling, and data analysis. Following this, the application process of the above methods uses northern Anhui as an example, and evaluates the sustainable agricultural development ability, pure technical and scale efficiency, and scale return of six cities in northern Anhui, and puts forward optimization countermeasures and management enlightenment.

\section{Materials and Methods}

\subsection{Method Flow}

This paper establishes a data-driven method to measure, evaluate, and optimize the capability for sustainable development of agriculture. In terms of data collection, the evaluation index system is constructed by taking the agricultural resource utilization index and environmental pollution index as input indices, and farmers' income and total output of agriculture, forestry, animal husbandry, and fishery as output indices. In the data 
processing, the data standardization method and entropy weight method are used to further process and integrate the data. A data envelopment analysis model with constant return to scale and a data envelopment analysis model with variable return to scale are constructed. The quantitative evaluation of the ability for agricultural sustainable development and changing trend was realized. Based on the evaluation results, the main factors influencing the ability of agricultural sustainable development were analyzed, and then the targeted methods to improve the ability for agricultural sustainable development were put forward. The method flow is shown in Figure 1.

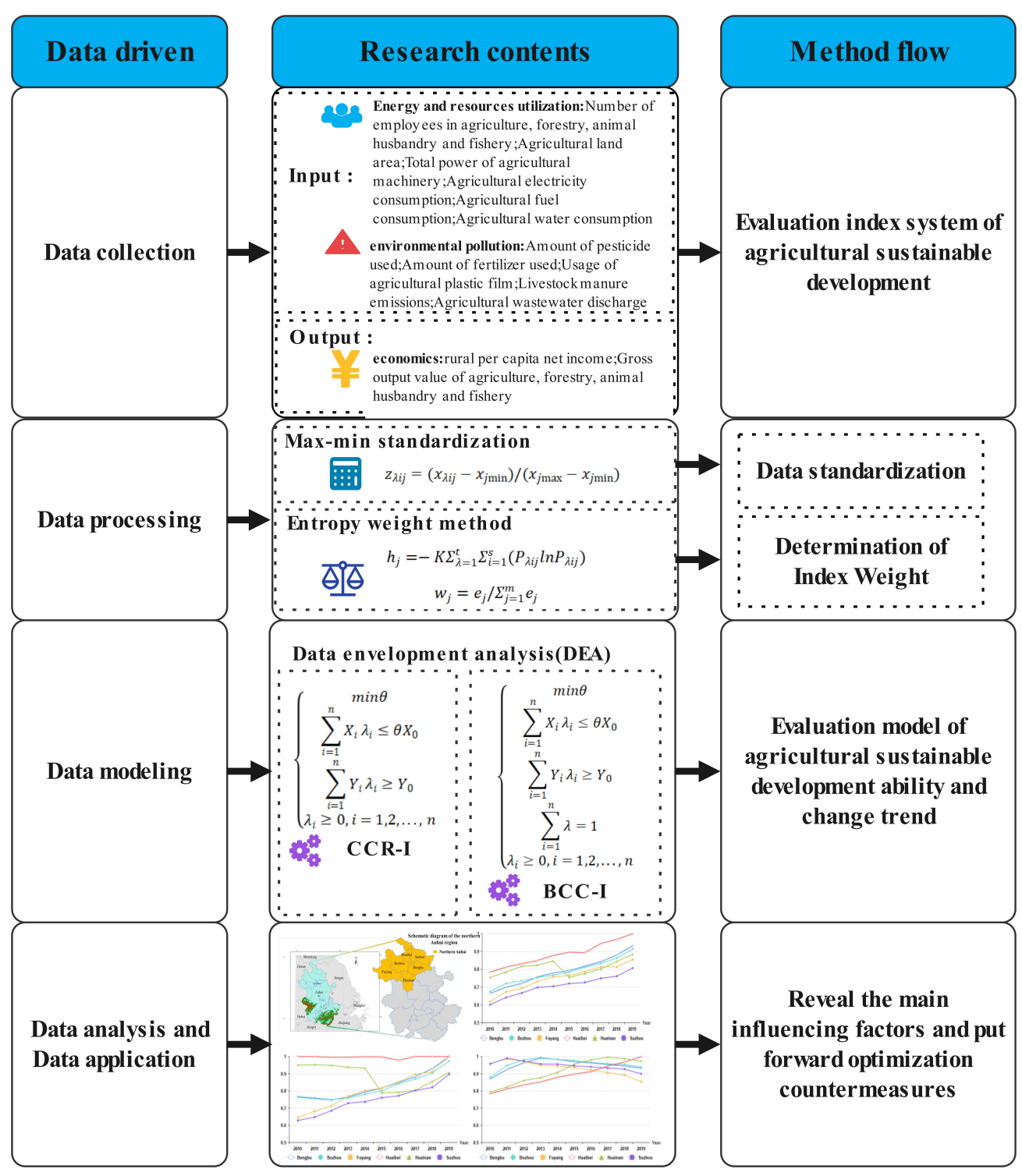

Figure 1. Method flow.

\subsection{Data Collection}

The design of the index system needs to be completed under the guidance of relevant theories of sustainable agricultural development [48]. The indices in this paper include two types, input and output, and can fully reflect the characteristics of several major elements of the agricultural sustainable development system, such as resources, environment, and economy. The selected output variables are agricultural output value and farmers' income, while the input variables are resource utilization and environmental pollution. The selected sample data is the panel data of six cities in northern Anhui during 2010-2019. The sorted and analyzed data can be applied to the comparative evaluation of the ability for 
sustainable agricultural development of different cities in the same period and can also be applied to the change trend evaluation of agricultural sustainable development ability of the same city in different periods, mainly from the Anhui Statistical Yearbook, China Statistical Yearbook, and China Agricultural Statistical Yearbook from 2010 to 2019. The data collection indicators are listed in Table 1.

Table 1. Evaluation index system of agricultural sustainable development ability.

\begin{tabular}{|c|c|c|c|}
\hline Indicator Type & Level I Index & Secondary Index & $\begin{array}{l}\text { Indicator } \\
\text { Attribute }\end{array}$ \\
\hline \multirow{2}{*}{$\begin{array}{l}\text { Output } \\
\text { indicators }\end{array}$} & \multirow[b]{2}{*}{ Economics } & Per capita net income of farmers (RMB) (0.3936) & + \\
\hline & & $\begin{array}{l}\text { Gross output value of agriculture, forestry, animal husbandry and } \\
\text { fishery }(10,000 \text { yuan })(0.6064)\end{array}$ & + \\
\hline \multirow{11}{*}{ Input index } & \multirow{6}{*}{$\begin{array}{l}\text { Energy and } \\
\text { resources utilization }\end{array}$} & $\begin{array}{l}\text { Number of employees in agriculture, forestry, animal husbandry } \\
\text { and fishery }(10,000)(0.1740)\end{array}$ & - \\
\hline & & Agricultural land area (thousand hectares) (0.2297) & - \\
\hline & & Total power of agricultural machinery $(10,000 \mathrm{~kW})(0.1434)$ & - \\
\hline & & Electricity consumption for agriculture (100 million kWh) (0.1249) & - \\
\hline & & Agricultural fuel consumption (ton) (0.1942) & - \\
\hline & & Agricultural water consumption (100 million cubic meters) (0.1338) & - \\
\hline & \multirow{5}{*}{ Environmental pollution } & Pesticide consumption (ton) (0.1916) & - \\
\hline & & Chemical fertilizer consumption (ton) (0.1670) & - \\
\hline & & Usage of agricultural plastic film (ton) (0.2315) & - \\
\hline & & Livestock manure discharge $(\mathrm{kg})(0.2119)$ & - \\
\hline & & Agricultural wastewater discharge (ton) (0.1980) & - \\
\hline
\end{tabular}

There are many indices in the comprehensive evaluation index system for sustainable agricultural development. To obtain comprehensive and objective data envelopment analysis (DEA) evaluation results, it is necessary to further generate DEA input and output comprehensive indices based on scientifically establishing the evaluation index system.

\subsection{Data Processing}

\subsubsection{Data Standardization Method}

Common data standardization methods involve Max-min standardization and z-score standardization. In this study, the Max-min standardization method is used to standardize the original index values; the specific calculation steps are as follows: First, an initial data matrix is constructed, with $t$ years, $s$ cities, and $n$ indices, forming an original data matrix:

$X=\left\{x_{\lambda i j}\right\}(1 \leq \lambda \leq t ; 1 \leq i \leq s ; 1 \leq j \leq n)$, in which, $x_{\lambda i j}$ is the original data of the index $j$ of the $i$ city in the $\lambda$ year.

The Max-min data standardization method can be calculated by the following two equations:

$$
\begin{aligned}
& z_{\lambda i j}=\left(x_{\lambda i j}-x_{j \min }\right) /\left(x_{j \max }-x_{j \min }\right) \\
& z_{\lambda i j}=\left(x_{j \max }-x_{\lambda i j}\right) /\left(x_{j \max }-x_{j \min }\right)
\end{aligned}
$$

$z_{\lambda i j}$ represents standardized data, $x_{j \min }$ represents the minimum value of the original data of index $j$, and $x_{j \max }$ represents the maximum value of the original data of index $j$. In the formula, $z_{\lambda i j} \in[0,1]$ and is dimensionless. Equation (1) can be used for positive output index and reverse input index, and Equation (2) can be used for reverse output index and positive input index. In the evaluation index system of this study, the output indicators are all positive indicators, and the input indicators are all reverse indicators (see Table 1). The standardized calculation adopts Equation (1), and the processed matrix is written as $Z=\left\{z_{\lambda i j}\right\}$. 


\subsubsection{Index Synthesis and Weight Determination Method}

Commonly used methods for comprehensive index generation include principal component analysis, the Delphi method, the analytic hierarchy process, and the entropy weight method, which can profoundly reflect the utility value of the index information entropy value. The index weight value given by the entropy weight method has high credibility, which is suitable for the research of sustainable development of the DEA method [49]. In this paper, entropy weight method is used to generate DEA input and output comprehensive indicators, including "agricultural output value and income" comprehensive indicators, "resource utilization" comprehensive indicators and "environmental pollution" comprehensive indicators. The specific generation steps are as follows:

To ensure that the logarithm is meaningful, data $z_{\lambda i j}$ is shifted based on the calculation result of 2.3.1 by one unit, and we call that $y_{\lambda i j}=z_{\lambda i j}+1$.

Let the information entropy value of each index be $h_{j}$, then $h_{j}=-K \sum_{\lambda=1}^{t} \sum_{i=1}^{S}\left(P_{\lambda i j} l n P_{\lambda i j}\right)$, where $P_{\lambda i j}=y_{\lambda i j} / \sum_{\lambda=1}^{t} \sum_{i=1}^{s} y_{\lambda i j}$ and $K=1 / \ln (t \times s)$.

Let the weight value of each index be $w_{j}$, then $w_{j}=e_{j} / \sum_{j=1}^{m} e_{j}$, where $e_{j}=1-h_{j}$, and $m$ is the number of secondary indices under the corresponding primary index. Obviously, $\sum_{j=1}^{m} w_{j}=1$ and $0 \leq w_{j} \leq 1$.

\subsection{Data Modeling}

Data envelopment analysis (DEA) is an efficiency evaluation method proposed by Charnes, a famous American logistics scientist in 1978 [50]. It has become a common and important analysis tool, and research means in the fields of management science, system engineering, decision analysis, and evaluation technology. Moreover, there are many types of data envelopment analysis models, which can be divided into input-oriented data envelopment analysis models and output-oriented data envelopment analysis model according to the input- and output-oriented classification. According to the classification of returns to scale, it can be divided into the constant data envelopment analysis model of returns to scale, and scale variable data envelopment analysis model.

In this study, the data envelopment analysis model with constant return to scale (this method was proposed by Charnes, Cooper, and Rhodes, hence it is commonly known as the CCR model [50]) and data envelopment analysis model with variable return to scale (this method was proposed by Banker, Charnes, and Cooper, hence it is commonly known as the BCC model [51]) were selected from the input perspective to obtain comprehensive technical efficiency, pure technical efficiency, scale efficiency, and return to scale. The comprehensive technical efficiency obtained by the DEA model can reflect the degree to which the production process of a decision-making unit (DMU) reaches the highest level. Under the condition that the output remains unchanged, the comprehensive technical efficiency is measured by the degree of input minimization. This is in line with the idea of reducing resources and pollution, and ensuring stable output advocated by sustainable development. Therefore, it is appropriate to use the DEA method to quantitatively study sustainable development, and the comprehensive technical efficiency value can reflect the overall level of agricultural sustainable development capability [52,53].

\subsubsection{Constant Return to Scale Model}

It is assumed that there are $n$ decision-making units $D M U_{i}(i=1,2, \cdots, n)$ in the evaluation process, and the $n$ decision-making units meet the homogeneity hypothesis and are all comparable. Each decision-making unit has $t$ input elements and obtains $s$ outputs; therefore, the input and output vectors are:

$$
X_{i}=\left(x_{1 i}, x_{2 i}, \cdots x_{t i}\right)^{T}>0, i=1,2, \cdots n Y_{i}=\left(y_{1 i}, y_{2 i}, \cdots y_{s i}\right)^{T}>0, i=1,2, \cdots n
$$

$x_{j i}$ represents the input amount of the $j$ th input of the $i$ th DMU, where $x_{j i}>0$, and $y_{j i}$ represents the output amount of the $j$ th output of the $i$ th DMU, where $y_{j i}>0$. 
To unify and synthesize all decision-making units, it is necessary to assign values to each input and output so that the weight vectors of the input and output are:

$$
v=\left(v_{1}, v_{2}, \cdots v_{t}\right)^{T} u=\left(u_{1}, u_{2}, \cdots u_{s}\right)^{T}
$$

where $v_{j}$ represents the weight of the jth input and $u_{r}$ represents the weight of the $r$ th output. The efficiency evaluation index of each $D M U_{j}$ is defined as: $k_{i}=\frac{\sum_{r=1}^{s} u_{r} y_{r i}}{\sum_{j=1}^{t} v_{j} x_{j i}}$.

According to the above analysis, the CCR model for efficiency evaluation of $D M U_{i_{0}}$ is $\left(\right.$ note $X_{0}=X_{i_{0}}, Y_{0}=Y_{i_{0}}$ ):

$$
\begin{gathered}
M A X k_{i_{0}}=\frac{\sum_{r=1}^{s} u_{r} y_{r i_{0}}}{\sum_{j=1}^{t} v_{j} x_{j i_{0}}} \\
\text { s.t. }\left\{\begin{array}{c}
\frac{\sum_{r=1}^{s} u_{r} y_{r i}}{\sum_{j=1}^{t} v_{j} x_{j i}} \leq 1, i=1,2, \cdots n \\
v=\left(v_{1}, v_{2}, \cdots v_{t}\right)^{T} \geq 0 \\
u=\left(u_{1}, u_{2}, \cdots u_{s}\right)^{T} \geq 0
\end{array}\right.
\end{gathered}
$$

The Charnes-Cooper transformation can be used to transform it into the following equivalent linear model:

$$
\left\{\begin{array}{c}
\max \mu^{T} Y_{0} \\
\text { s.t. } \omega^{T} X_{i}-\mu^{T} Y_{i} \geq 0, i=1,2, \ldots, n \\
\omega^{T} X_{0}=1 \\
\omega \geq 0, \mu \geq 0
\end{array}\right.
$$

According to the linear dual theory, the dual programming model of Equation (3) is obtained as follows:

$$
\left\{\begin{array}{c}
\min \theta \\
\sum_{i=1}^{n} X_{i} \lambda_{i} \leq \theta X_{0} \\
\sum_{i=1}^{n} Y_{i} \lambda_{i} \geq Y_{0} \\
\lambda_{i} \geq 0, i=1,2, \ldots, n
\end{array}\right.
$$

In Equation (4), $\theta$ is the parameter to be estimated, the optimal solution $\theta^{*}$ is the efficiency value of DMU, and $0 \leq \theta^{*} \leq 1$. When $\theta^{*}=1$, it shows that DMU is on the front of efficiency, and there is no possibility of equal ratio reduction of various inputs, so it is DEA effective. When $\theta^{*}<1$, DEA is invalid, and input and output can be further optimized to improve efficiency; the higher $\theta^{*}$ is, the higher the efficiency value is, and the overall level of ability for sustainable development is higher in this study.

\subsubsection{Variable Return to Scale Model}

The CCR model contains the following premise: the return to scale is unchanged. This model can only measure "comprehensive technical efficiency." When the CCR model DEA is effective, this decision unit is technically effective and scale effective. However, to further explore the problems of "pure technical efficiency" and "scale efficiency," the BCC model needs to be introduced. When the return to scale is assumed to be variable, it is called the $\mathrm{BBC}$ model, that is, the constraint condition $\sum_{i=1}^{n} \lambda=1$ is introduced into Equation (4), and the expression of BCC model is obtained as follows:

$$
\left\{\begin{array}{c}
\min \theta \\
\sum_{i=1}^{n} X_{i} \lambda_{i} \leq \theta X_{0} \\
\sum_{i=1}^{n} Y_{i} \lambda_{i} \geq Y_{0} \\
\sum_{i=1}^{n} \lambda=1 \\
\lambda_{i} \geq 0, i=1,2, \ldots, n
\end{array}\right.
$$

The optimal solution of Equation (5) is $\theta^{*}, 0 \leq \theta^{*} \leq 1$. 
Comparing the CCR model with the BCC model, the efficiency obtained by the two models has different meanings in economics. Comprehensive technical efficiency (TE) is obtained using the CCR model, and pure technical efficiency (PTE) is obtained by the BCC model. They satisfy the relationship: comprehensive technical efficiency $(\mathrm{TE})=$ pure technical efficiency (PTE)* scale efficiency (SE). By solving Equations (4) and (5) simultaneously, comprehensive TE, PTE, and SE can be obtained.

In this paper, comprehensive technical efficiency (TE) refers to the sustainable development ability of the evaluated decision-making unit (DMU), which is a compound quantity.

In this study, pure technical efficiency (PTE) refers to the ability of the DMU to obtain output under a given agricultural input. When pure technical efficiency is effective, given the existing output, the agricultural system only needs to consume the least amount of resources, that is, the input-output efficiency of the system is in the best state.

SE refers to the degree to which the DMU deviates from the return to scale when the return to scale decreases or increases. In other words, when the DMU is under the condition of constant return to scale, it is scale-effective; otherwise, it is scale-ineffective.

Return to scale refers to a state in which the agricultural production of the decisionmaking unit (DMU) is in. When the input is expanded $n$ times, the output expands with the expansion of the input. The CCR model based on Section 2.4.1 can obtain the optimal solution $\lambda^{*}$. If the $\mathrm{SE}=1$, it means that when the agricultural input is expanded by $\mathrm{N}$ times, the output index is also expanded $\mathrm{N}$ times, which is called the return to scale unchanged. If the SE is less than 1 , and $\sum \lambda^{*}<1$ in any optimal solution, it means that when the input is expanded $\mathrm{n}$ times and the output is expanded by more than $\mathrm{n}$ times, it is called increasing returns to scale. Currently, it is necessary to consider increasing the scale of agricultural input. If $\mathrm{SE}$ is less than 1 , and $\sum \lambda^{*}>1$ in any optimal solution, it means that a given input is expanded by $n$ times, and the expansion of output is less than $n$ times, which is called diminishing returns to scale. At this time, we should consider reducing the scale of agricultural inputs.

\section{Case Study}

Using the above research methods, we considered agriculture in northern Anhui for our case study. According to the calculation results, this paper discusses the agricultural production efficiency, SE, and sustainable development ability in northern Anhui. Consequently, we propose countermeasures for sustainable agricultural development in northern Anhui and summarize the management enlightenment.

\subsection{Introduction of Northern Anhui Agricultural Region}

North Anhui is located in the north of Anhui, China, bordering Jiangsu in the east, southern Anhui in the south, Henan in the west, and Shandong in the north. The terrain is mainly plains, including the vast Huaibei Plain. Northern Anhui is an important traditional grain-producing area in China. Cities in northern Anhui include: Bengbu, Bozhou, Fuyang, Huaibei, Suzhou, and Huainan, and their locations are shown in Figure 2. It is of great significance to study the capacity for the development of sustainable agriculture in cities in northern Anhui, summarize the laws of agricultural development and the experience of agricultural development in advantageous areas, and identify the shortcomings of agricultural development in areas with weak agricultural production, to effectively allocate agricultural development resources and promote the improvement of capacity for agricultural sustainable development in northern Anhui. 


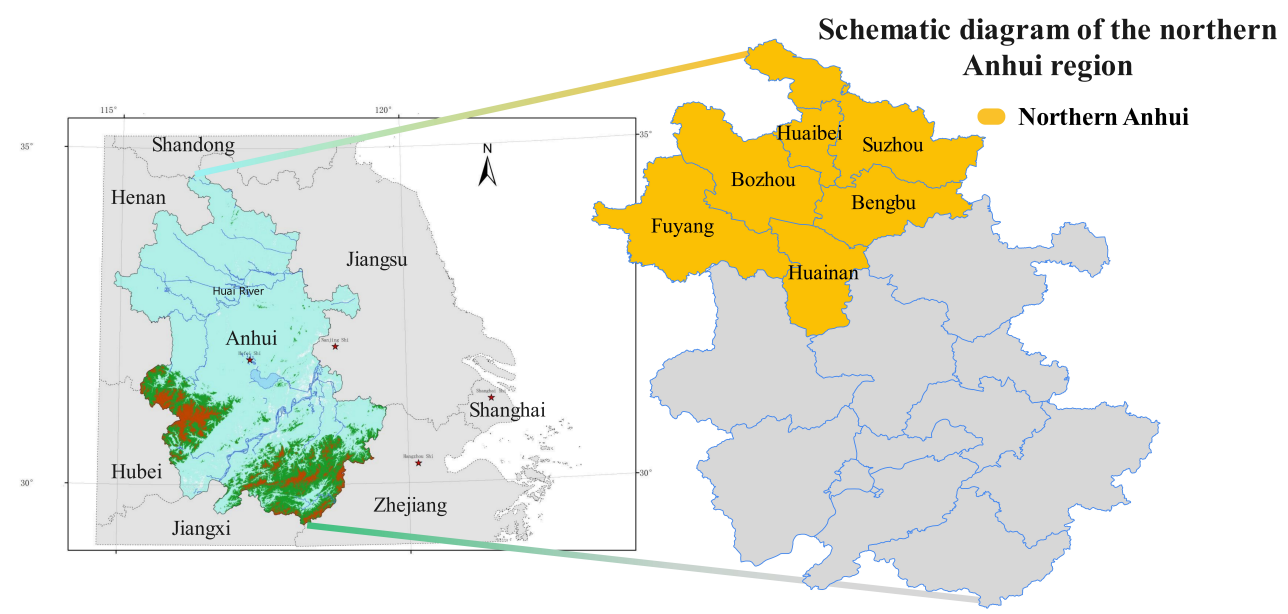

Figure 2. Schematic diagram of administrative divisions in northern Anhui.

\subsection{Results}

\subsubsection{Data Processing Results}

According to the method described in Section 2.3, the data of six cities in northern Anhui from 2010 to 2019 were standardized, and the corresponding weights were calculated (see Table 1 for the calculation results of weights). The values of the three comprehensive indices of agricultural output value, income, resource utilization, and environmental pollution were obtained (Appendix A).

\subsubsection{Calculation Results of Comprehensive Technical Efficiency}

The output data (Table A1) and input data (Tables A2 and A3) were imported into MaxDEA8 software, and the CCR model was used to evaluate the comprehensive TE of six cities from 2010 to 2019 (comprehensive TE reflects the ability for sustainable development of agriculture in each city), and the specific values are shown in Table 2.

Table 2. Calculation results of comprehensive technical efficiency.

\begin{tabular}{ccccccc}
\hline & Bengbu & Bozhou & Fuyang & Huaibei & Huainan & Suzhou \\
\hline 2010 & 0.66487 & 0.67570 & 0.61865 & 0.78379 & 0.75457 & 0.60097 \\
2011 & 0.69883 & 0.72028 & 0.67313 & 0.81184 & 0.78430 & 0.64150 \\
2012 & 0.72069 & 0.73546 & 0.69327 & 0.83171 & 0.81736 & 0.66674 \\
2013 & 0.75732 & 0.75400 & 0.73071 & 0.84946 & 0.82310 & 0.69835 \\
2014 & 0.77953 & 0.76724 & 0.75769 & 0.87806 & 0.84716 & 0.70450 \\
2015 & 0.79270 & 0.78317 & 0.76529 & 0.89640 & 0.75433 & 0.71956 \\
2016 & 0.81808 & 0.81258 & 0.78700 & 0.89359 & 0.77685 & 0.72562 \\
2017 & 0.84297 & 0.83347 & 0.81413 & 0.94543 & 0.80176 & 0.74927 \\
2018 & 0.87993 & 0.86219 & 0.81426 & 0.96830 & 0.84356 & 0.76071 \\
2019 & 0.93238 & 0.91365 & 0.85392 & 1.00000 & 0.88459 & 0.80648 \\
\hline Mean value & 0.78873 & 0.78577 & 0.75081 & 0.88586 & 0.80876 & 0.70737 \\
\hline
\end{tabular}

According to the calculation results in Table 2, the corresponding line chart is drawn to reflect the changing trends and characteristics concerning the capacity for sustainable development of each city from 2010 to 2019, as shown in Figure 3. Based on the average value of the capacity for sustainable development of the six cities from 2010 to 2019 in Table 2, the radar chart is drawn to reflect the overall level of the capacity for sustainable development of each city, as shown in Figure 4. 


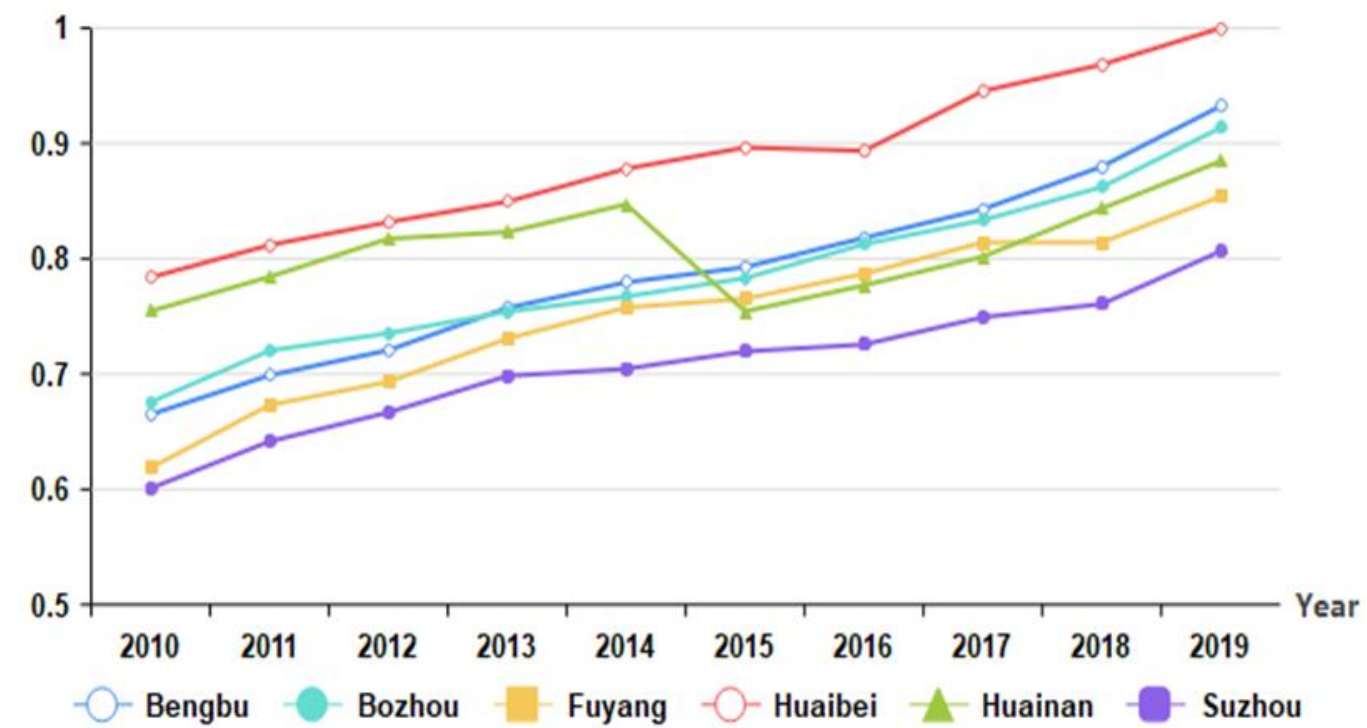

Figure 3. Comprehensive technical efficiency evaluation results.

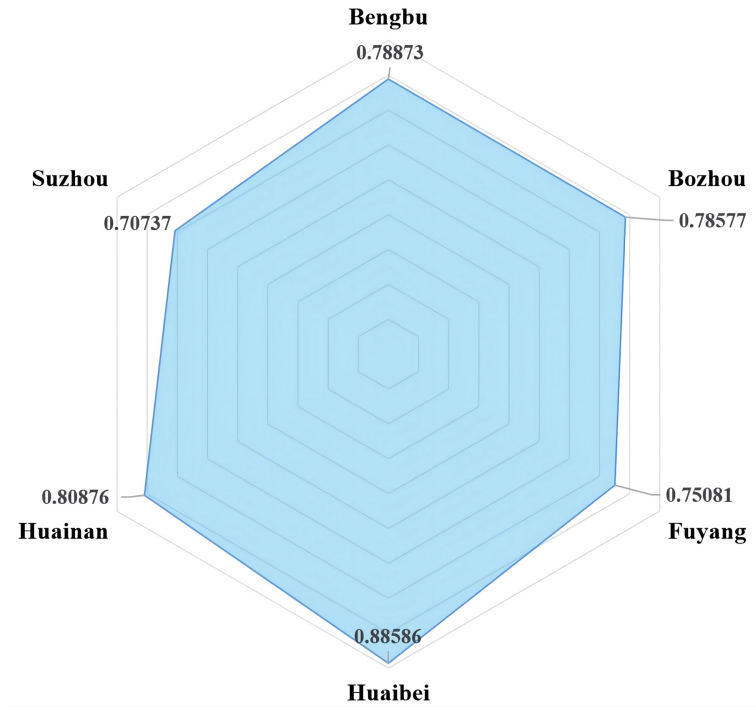

Figure 4. Average comprehensive technical efficiency of each city for 2010-2019.

During the timeframe of 2010-2019, except for Huainan, the overall agricultural sustainable development capacity of six cities in northern Anhui showed a steady upward trend, but lower than the previous level observed in the period 2015-2018. During this period, the capacity for agricultural sustainable development gradually improved and recovered to a level exceeding that from 2014 to 2019. This study specifically discusses the causes of the fluctuations in Section 3.3. In comparing the six cities, Huaibei City has the best sustainable development ability (0.886), while Suzhou City has the weakest sustainable development ability, which is only 0.707 .

\subsubsection{Calculation Results of Pure Technical Efficiency and Scale Efficiency}

The input and output data were imported into MaxDEA8 software, and the BCC model was used to evaluate the PTE of the six cities from 2010 to 2019. See Table 3 for details. Furthermore, using the numerical relationship in Section 2.4.2 (Comprehensive Technical Efficiency $(\mathrm{TE})=$ Pure Technical Efficiency (PTE)* Scale Efficiency (SE)), the corresponding scale efficiency value can be calculated, see Table 4 for details. 
Table 3. Calculation results of pure technical efficiency.

\begin{tabular}{ccccccc}
\hline & Bengbu & Bozhou & Fuyang & Huaibei & Huainan & Suzhou \\
\hline 2010 & 0.76402 & 0.76719 & 0.64406 & 1.00000 & 0.95033 & 0.62765 \\
2011 & 0.75522 & 0.75946 & 0.68192 & 0.99954 & 0.95236 & 0.64694 \\
2012 & 0.74733 & 0.74905 & 0.71359 & 0.99562 & 0.94893 & 0.68479 \\
2013 & 0.76405 & 0.75795 & 0.76911 & 0.99574 & 0.93787 & 0.72902 \\
2014 & 0.79223 & 0.77954 & 0.80135 & 0.99879 & 0.93312 & 0.73680 \\
2015 & 0.81723 & 0.80130 & 0.81736 & 0.99759 & 0.78871 & 0.76034 \\
2016 & 0.84866 & 0.84085 & 0.85274 & 0.97880 & 0.79145 & 0.77140 \\
2017 & 0.88319 & 0.86959 & 0.89768 & 1.00000 & 0.80427 & 0.80230 \\
2018 & 0.92965 & 0.90371 & 0.91120 & 1.00000 & 0.85369 & 0.82023 \\
2019 & 1.00000 & 0.97271 & 1.00000 & 1.00000 & 0.90771 & 0.89623 \\
\hline Mean value & 0.83016 & 0.82014 & 0.80890 & 0.99661 & 0.88684 & 0.74757 \\
\hline
\end{tabular}

Table 4. Calculation results of scale efficiency.

\begin{tabular}{lcccccc}
\hline & Bengbu & Bozhou & Fuyang & Huaibei & Huainan & Suzhou \\
\hline 2010 & 0.87022 & 0.88074 & 0.96054 & 0.78379 & 0.79401 & 0.95749 \\
2011 & 0.92533 & 0.94842 & 0.98712 & 0.81221 & 0.82353 & 0.99159 \\
2012 & 0.96435 & 0.98184 & 0.97152 & 0.83537 & 0.86135 & 0.97363 \\
2013 & 0.99119 & 0.99479 & 0.95007 & 0.85309 & 0.87762 & 0.95792 \\
2014 & 0.98397 & 0.98421 & 0.94552 & 0.87912 & 0.90788 & 0.95616 \\
2015 & 0.96998 & 0.97737 & 0.93630 & 0.89856 & 0.95641 & 0.94636 \\
2016 & 0.96396 & 0.96638 & 0.92291 & 0.91294 & 0.98155 & 0.94065 \\
2017 & 0.95445 & 0.95846 & 0.90693 & 0.94543 & 0.99688 & 0.93391 \\
2018 & 0.94651 & 0.95406 & 0.89361 & 0.96830 & 0.98813 & 0.92743 \\
2019 & 0.93238 & 0.93928 & 0.85392 & 1.00000 & 0.97453 & 0.89986 \\
\hline
\end{tabular}

According to the calculation results in Tables 3 and 4, a line chart is drawn to reflect the changing trend of PTE and SE of each city from 2010 to 2019, as shown in Figures 5 and 6. Except for Huaibei, the change trend of PTE in other cities is similar to that of comprehensive TE, which is basically in a state of steady improvement (in Huainan, the efficiency declined in 2015, and the trend was similar to the comprehensive TE).

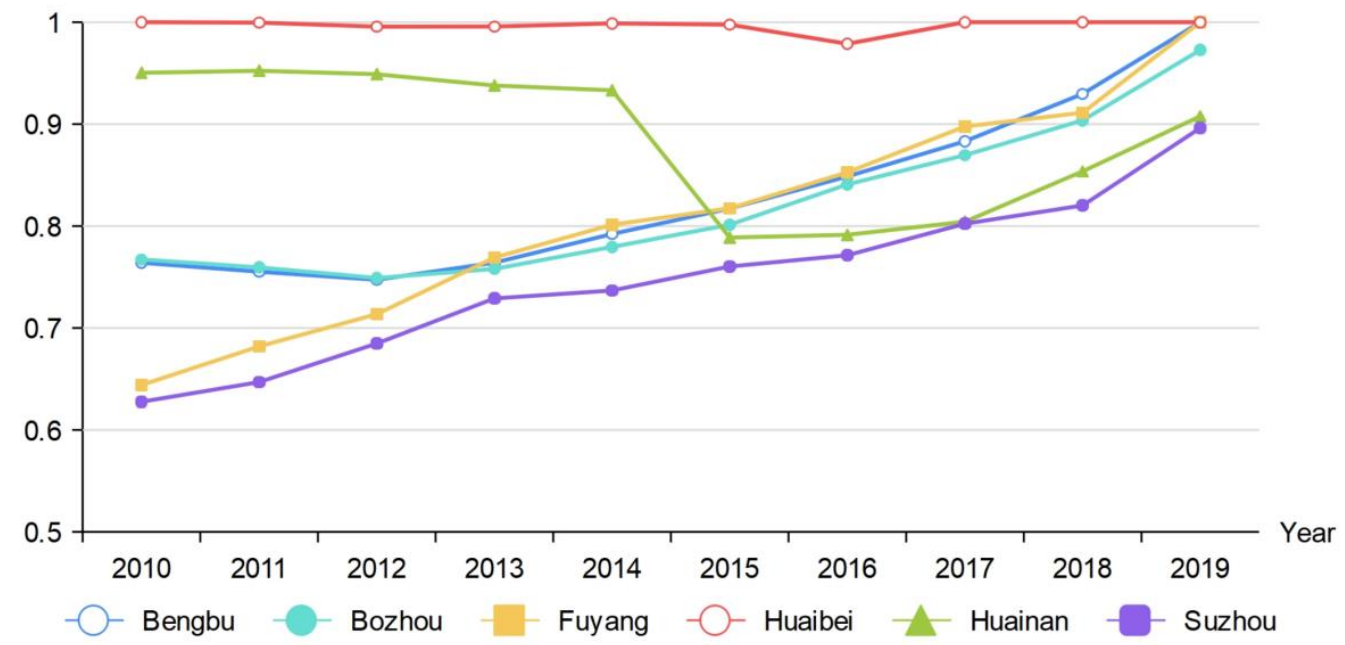

Figure 5. Calculation results of pure technical efficiency. 


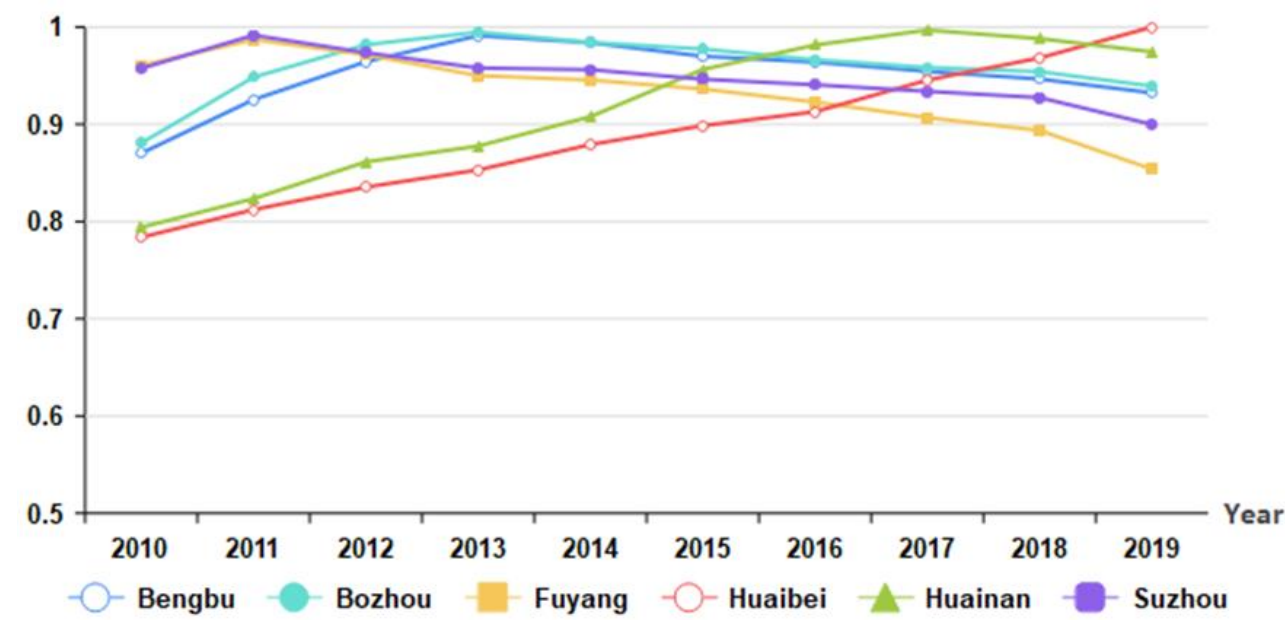

Figure 6. Results of scale efficiency evaluation.

\subsubsection{Calculation Result of Return to Scale}

The input and output data are imported into MaxDEA8 software, and the calculation results of returns to scale can be obtained, as shown in Table 5. In the table, DRS indicates decreasing returns to scale, "-" indicates constant returns to scale, and IRS indicates increasing returns to scale.

Table 5. Calculation results of return to scale.

\begin{tabular}{ccccccc}
\hline & Bengbu & Bozhou & Fuyang & Huaibei & Huainan & Suzhou \\
\hline 2010 & IRS & IRS & IRS & IRS & IRS & IRS \\
2011 & IRS & IRS & DRS & IRS & IRS & DRS \\
2012 & IRS & IRS & DRS & IRS & IRS & DRS \\
2013 & DRS & DRS & DRS & IRS & IRS & DRS \\
2014 & DRS & DRS & DRS & IRS & IRS & DRS \\
2015 & DRS & DRS & DRS & IRS & IRS & DRS \\
2016 & DRS & DRS & DRS & IRS & IRS & DRS \\
2017 & DRS & DRS & DRS & IRS & DRS & DRS \\
2018 & DRS & DRS & DRS & IRS & DRS & DRS \\
2019 & DRS & DRS & DRS & - & DRS & DRS \\
\hline
\end{tabular}

It can be seen from Table 5 that only Huaibei achieved the same return to scale in 2019, while other DMUs were in a state of decreasing or increasing return to scale, which indicates that the production scale is not in the best state. Notably, only when the production scale and production technology are in the optimal state can the agricultural production efficiency be the highest, and the ability for sustainable development be the best.

\subsection{Discussion}

3.3.1. Dynamic Discussion on the Ability for Agricultural Sustainable Development in Northern Anhui

It can be seen from Figure 3 that the overall capacity for sustainable development of each city shows a trend of continuous improvement, which indicates that each city is paying more and more attention to the sustainable development of agriculture, continuously adjusting the industrial structure, improving the technical level of agricultural production, and continuously reducing the input of environment and resources and improving the output. Among cities from 2010 to 2019, only Huaibei, in 2019, has an evaluation result of 1, which is DEA effective; in other years, the cities did not achieve DEA efficiency, suggesting that the agricultural sustainable development capacity of cities in northern Anhui was still weak as a whole, and there was still room for further optimization. 
The PTE of Huaibei was essentially maintained above 0.99 from 2010 to 2019, which indicates that its production status has consistently remained high, but it was only in 2019 that DEA efficiency was achieved, primarily because the production scale was not in the best state (see Figure 6). Due to the continuous improvement of SE, the capacity for sustainable development of Huaibei is continuously improving. In 2019, Huaibei has both an effective scale and effective technology; as such, it has good capacity for sustainable development. Comparing Figures 3, 5 and 6, the main reason for the decline of comprehensive TE in Huainan is the decline of PTE, which shows several resources and environmental inputs that fail to attain the proper output. By further reviewing the initial survey data, we found that the total power of agricultural machinery, agricultural electricity consumption, agricultural fuel consumption, pesticide consumption, fertilizer consumption and agricultural plastic film consumption in Huainan have all increased significantly during the period 2015-2018, and the total output value of agriculture, forestry, animal husbandry and fishery has increased relatively little. After consulting relevant data, we found that Huainan carried out agricultural construction and development of the collapsed land over 2013-2014. Because the water quality, atmosphere, and vegetation in the collapsed area suffered serious damage, the risk of natural disasters was high [54,55], and farming convenience was poor, which was not conducive to the sustainable development of agriculture, such that the production efficiency decreased significantly. According to the changing trend of other cities, the SE is essentially above 0.85 (Figure 6). The change in scale is not significant, and the change trend of PTE (Figure 5) is similar to that of comprehensive TE (Figure 3). This shows that the main factor affecting the ability for sustainable development of Suzhou, Fuyang, Bengbu, and Bozhou is PTE. With the continuous improvement of production technology and the enhancement of environmental protection awareness, sustainable development ability is constantly increasing.

\subsubsection{Static Discussion on the Ability for Agricultural Sustainable Development in} Northern Anhui

According to the calculation results of average comprehensive TE (Figure 4), Huaibei has the highest capability for sustainable development; contrastingly, Suzhou has the weakest capability for sustainable development, which illustrates that the capability for sustainable development of agriculture is not directly proportional to the production scale. By comparing the input and output data of the two cities in 2019, the comprehensive indices for Huaibei are 1.07016, 1.02135, and 1.35712 for resource utilization, environmental pollution, and agricultural output value and income from 2010 to 2019, respectively. The values of these indices for Suzhou are 1.70867, 1.70332, and 1.74752 for resource utilization, environmental pollution, and agricultural output value and income from 2010 to 2019, respectively. It is not difficult to find that Huaibei has obtained relatively large output with relatively few resources and environmental inputs, which further confirms and intuitively reflects that Huaibei has strong capability for sustainable development, whereas Suzhou's capability for sustainable development needs to be urgently improved.

Table 3 shows that the PTE of Bengbu, Fuyang, and Huaibei reached the optimal state in 2019. According to the calculation results of returns to scale (see Table 5), Bengbu and Fuyang are in a state of decreasing scale. According to the specific conditions of cities, it is necessary to reduce the input of various resources, appropriately reduce the scale of agricultural production, and realize the sustainable development of agriculture. The pure technical and scale efficiencies of other cities are ineffective, and the SE is declining; we should improve agricultural production technology, reduce environmental pollution emissions, appropriately reduce the scale of agricultural input, and so on, to improve the sustainable development ability of agriculture.

\subsection{Policy Recommendations}

Based on the results of the evaluation and discussion, the following suggestions are put forward to improve the sustainable development ability of agriculture in northern Anhui: 
(1) Some areas in northern Anhui still need to improve their production efficiency, and a reasonable input-output ratio is an inevitable requirement for the sustainable development of agriculture in northern Anhui. Hence, we should increase investment in agricultural science and technology, establish an agricultural innovation system in Anhui Province, realize the transformation from traditional agriculture to science and technology agriculture and digital agriculture, pay attention to improvements in technical and management levels, and provide sufficient technical support for the sustainable development of agriculture. (2) Encourage the development of water-saving agriculture and ecological agriculture, strictly limit the scale and layout of industries that waste resources and cause serious pollution, increase the financial and tax support for sustainable development, establish and improve the reward mechanism for sustainable development, and normalize and standardize the reward work for sustainable development. (3) The low comprehensive efficiency in most areas of northern Anhui is affected by SE. Therefore, the agricultural planting structure and agricultural industrial layout should be optimized reasonably, and unnecessary input of agricultural labor, capital, and land should be reduced. Hence, it is necessary to actively develop high-quality agriculture and characteristic agriculture to transform the agricultural planting structure to the direction of excellent quality and benefit; to ensure food security and food production capacity, efficient cash crops should be vigorously developed.

\subsection{Management Implications}

To achieve sustainable development, the agricultural production system must be sustainable in terms of resources, environment, and economy. This requires the realization of three important goals: increasing grain output and farmers' income, rationally utilizing resources and protecting the environment. From the perspective of agricultural production activities, we should try our best to improve agricultural output and farmers' income level, and the smaller the input for resources and environment, the better. In other words, the higher the utilization efficiency of resources and environment, the better. Compared with the existing literature [12,45], this study has the following advantages: First, the evaluation index system is more scientific and comprehensive, which can fully reflect the consumption of resources and energy, environmental pollution, and agricultural economic development level, providing a theoretical foundation for objectively judging the ability of agricultural sustainable development. Second, this study constructs the evaluation model and quantitatively evaluates the regional agricultural sustainable development ability, realizes the comparison between cities, and effectively evaluates the sustainable development trend. Finally, through data analysis, we can accurately determine the key factors affecting the regional sustainable development ability, and provide decision-making support for the government and agricultural researchers dealing with environmental pollution and resource shortage. Altogether, the model has important practical significance in the early warning and control of sustainable development. Combined with the above research and conclusions, we obtain the following management enlightenment:

(1) Sustainable development of agriculture is a complex and dynamic system. With the development of the times and the changes of people's needs, the theory of sustainable development is also changing. Therefore, it is necessary to continuously optimize and improve the evaluation index system according to the change of sustainable development theory, to better reflect the sustainable development ability of agriculture. To better cope with environmental pollution and global problems such as excessive consumption of resources, and improve the agricultural economy level, a comprehensive index system is herewith constructed, which considers factors such as livestock manure, agricultural wastewater and fertilizer consumption, as well as land, manpower, and energy utilization. (2) Improving the sustainable development ability of agriculture is the inevitable pursuit for enhancing agricultural competitiveness, ensuring social stability, and improving farmers' living standards. It is necessary to use mathematical model to evaluate ability for sustainable development. (3) The level of regional agricultural sustainable development is 
an important symbol of a regional sustainable development level, and many government officials and scholars are actively proposing various countermeasures to promote agricultural development; achieved by fully using the data-driven method, we can determine the problems and defects in agricultural development objectively and simply.

\section{Conclusions}

At present, agriculture is faced with multiple pressures related to resources and the environment at a global scale, which severely hinders sustainable development. Therefore, in order to better respond to the above challenges, fill in the gaps in research, and realize the high-quality development of agriculture and scientific evaluation of the sustainable development, in this study a data-driven method to measure, evaluate, and optimize sustainable agricultural development capability was proposed. The main conclusions are as follows:

(1) The evaluation index system of agricultural sustainable development ability was constructed from the perspectives of inputs and outputs, where the utilization of various resources in the agricultural production process and environmental pollution caused by agriculture are inputs, and the agricultural output value and farmers' income level are outputs. (2) A model to evaluate the sustainable development ability of regional agriculture was constructed. (3) A data-driven mechanism was constructed to improve the sustainable development of agriculture. According to the analysis results of the samples, this paper puts forward some countermeasures from the angle of reasonable control of production scale and reduction of environmental load and provides a reference for government departments to guide and standardize the better development of regional agriculture.

This study provides a good reference for the sustainable development of regional agriculture. In addition to assessing the ability for sustainable development and changing trend, our study also explains the ability of a region or sector to attain sustainable development, while simultaneously assessing the degree of this ability. Furthermore, our study provides a basis for early warning and regulation of sustainable development, and theoretical and methodological support for the improvement and optimization of agricultural sustainable development capability. In future research, other regions can be added to realize the evaluation and optimization of agricultural sustainable development capability for a larger area.

Author Contributions: Conceptualization, M.L. and F.L.; methodology, M.L. and J.C.; software, M.L. and J.C.; validation, F.L. and J.C.; formal analysis, M.L.; investigation, F.L. and J.C.; resources, M.L.; data curation, F.L. and J.C.; writing-original draft preparation, M.L.; writing-review and editing, F.L.; visualization, M.L.; supervision, F.L. and J.C.; project administration, F.L. All authors have read and agreed to the published version of the manuscript.

Funding: Research results of Philosophy and Social Science Planning Project of Anhui Province, project Approval Number: AHSKQ2020D79.

Institutional Review Board Statement: Not applicable.

Informed Consent Statement: Not applicable.

Data Availability Statement: All data generated or analyzed during this study are included in this published article.

Conflicts of Interest: The authors declare no conflict of interest. 


\section{Appendix A}

Table A1. Data processing results of agricultural output value and income from 2010 to 2019.

\begin{tabular}{lcccccc}
\hline & Bengbu & Bozhou & Fuyang & Huaibei & Huainan & Suzhou \\
\hline 2010 & 1.17236 & 1.18724 & 1.29013 & 1.04366 & 1.05809 & 1.28541 \\
2011 & 1.24792 & 1.28336 & 1.39877 & 1.08268 & 1.09826 & 1.38389 \\
2012 & 1.30176 & 1.33110 & 1.45440 & 1.11455 & 1.15037 & 1.44650 \\
2013 & 1.39170 & 1.37727 & 1.54203 & 1.13897 & 1.18283 & 1.50829 \\
2014 & 1.40953 & 1.42080 & 1.56255 & 1.17491 & 1.22569 & 1.51569 \\
2015 & 1.46024 & 1.45101 & 1.60652 & 1.20181 & 1.29475 & 1.55871 \\
2016 & 1.51543 & 1.50329 & 1.67671 & 1.23288 & 1.33068 & 1.58535 \\
2017 & 1.56595 & 1.54416 & 1.72970 & 1.26680 & 1.36911 & 1.61848 \\
2018 & 1.61161 & 1.56811 & 1.76380 & 1.30218 & 1.40426 & 1.65209 \\
2019 & 1.70210 & 1.65634 & 1.88109 & 1.35712 & 1.46404 & 1.74752 \\
\hline
\end{tabular}

Table A2. Data processing results of resource utilization from 2010 to 2019.

\begin{tabular}{ccccccc}
\hline & Bengbu & Bozhou & Fuyang & Huaibei & Huainan & Suzhou \\
\hline 2010 & 1.40272 & 1.54727 & 1.64444 & 1.05000 & 1.10574 & 1.68664 \\
2011 & 1.40814 & 1.55387 & 1.63861 & 1.05162 & 1.10421 & 1.70112 \\
2012 & 1.42434 & 1.55908 & 1.65430 & 1.05672 & 1.10982 & 1.71078 \\
2013 & 1.47134 & 1.55725 & 1.66408 & 1.05731 & 1.20166 & 1.70310 \\
2014 & 1.42583 & 1.58116 & 1.62619 & 1.05514 & 1.21835 & 1.69651 \\
2015 & 1.45259 & 1.60459 & 1.65535 & 1.05721 & 1.39739 & 1.70816 \\
2016 & 1.47325 & 1.49940 & 1.68000 & 1.18390 & 1.46773 & 1.72285 \\
2017 & 1.49051 & 1.59754 & 1.67535 & 1.05660 & 1.46779 & 1.70333 \\
2018 & 1.48741 & 1.62302 & 1.70811 & 1.06045 & 1.42838 & 1.71256 \\
2019 & 1.46141 & 1.64387 & 1.73709 & 1.07016 & 1.41749 & 1.70867 \\
\hline
\end{tabular}

Table A3. Processing results of environmental pollution data from 2010 to 2019.

\begin{tabular}{ccccccc}
\hline & Bengbu & Bozhou & Fuyang & Huaibei & Huainan & Suzhou \\
\hline 2010 & 1.32704 & 1.32234 & 1.63770 & 1.00870 & 1.06215 & 1.69301 \\
2011 & 1.34654 & 1.34091 & 1.66753 & 1.03513 & 1.06751 & 1.72617 \\
2012 & 1.36727 & 1.36211 & 1.70922 & 1.03513 & 1.07531 & 1.75336 \\
2013 & 1.38300 & 1.37469 & 1.74324 & 1.03720 & 1.08150 & 1.76981 \\
2014 & 1.38041 & 1.39367 & 1.77997 & 1.04495 & 1.08886 & 1.79605 \\
2015 & 1.39474 & 1.39435 & 1.78310 & 1.04069 & 1.29176 & 1.80313 \\
2016 & 1.39412 & 1.39231 & 1.79218 & 1.03834 & 1.28912 & 1.79408 \\
2017 & 1.39806 & 1.39432 & 1.79417 & 1.03060 & 1.28514 & 1.76347 \\
2018 & 1.37838 & 1.36876 & 1.73422 & 1.02697 & 1.25283 & 1.70912 \\
2019 & 1.37389 & 1.36436 & 1.74189 & 1.02135 & 1.24557 & 1.70332 \\
\hline
\end{tabular}

\section{References}

1. Hayashi, K.; Llorca, L.P.; Bugayong, I.D.; Agustiani, N.; Capistrano, A. Evaluating the predictive accuracy of the weather-ricenutrient integrated decision support system (WeRise) to improve rainfed rice productivity in Southeast Asia. Agriculture 2021, 11, 346. [CrossRef]

2. Pylianidis, C.; Osinga, S.; Athanasiadis, I.N. Introducing digital twins to agriculture. Comput. Electron. Agric. 2021, $184,105942$. [CrossRef]

3. Li, M.; Guo, P.; Singh, V.P.; Yang, G. An uncertainty-based framework for agricultural water-land resources allocation and risk evaluation. Agric. Water Manag. 2016, 177, 10-23. [CrossRef]

4. Fei, R.; Lin, B. Estimates of energy demand and energy saving potential in China's agricultural sector. Energy 2017, 135, 865-875. [CrossRef]

5. Lahlou, F.Z.; Mackey, H.R.; Al-Ansari, T. Wastewater reuse for livestock feed irrigation as a sustainable practice: A socioenvironmental-economic review. J. Clean. Prod. 2021, 294, 126331. [CrossRef] 
6. Crouch, M.K.; Guerrero, B.; Amosson, S.; Marek, T.; Almas, L. Analyzing potential water conservation strategies in the Texas Panhandle. Irrig. Sci. 2020, 38, 559-567. [CrossRef]

7. Mu, L.; Fang, L.; Dou, W.; Wang, C.; Qu, X.; Yu, Y. Urbanization-induced spatiotemporal variation of water resources utilization in northwestern China: A spatial panel model based approach. Ecol. Indic. 2021, 125, 107457. [CrossRef]

8. Li, G.; Shi, M.; Zhou, D. How much will farmers be compensated for water reallocation from agricultural water to the local ecological sector on the edge of an oasis in the Heihe River Basin? Agric. Water Manag. 2021, 249, 106801. [CrossRef]

9. Jans, Y.; Bloh, W.V.; Schaphoff, S.; Müller, C. Global cotton production under climate change-Implications for yield and water consumption. Hydrol. Earth Syst. Sci. 2021, 25, 2027-2044. [CrossRef]

10. Liu, C.; Cai, W.; Zhai, M.; Zhu, G.; Zhang, C.; Jiang, Z. Decoupling of wastewater eco-environmental damage and China's economic development. Sci. Total Environ. 2021, 789, 147980. [CrossRef]

11. Gjorgievski, V.Z.; Markovska, N.; Pukšec, T.; Duić, N.; Foley, A. Supporting the 2030 agenda for sustainable development: Special issue dedicated to the conference on sustainable development of energy, water and environment systems 2019. Renew. Sustain. Energy Rev. 2021, 143, 110920. [CrossRef]

12. Daly, H.E. Toward some operational principles of sustainable development. Ecol. Econ. 1990, 2, 1-6. [CrossRef]

13. Barrett, S. Economic Growth and Environmental Quality Time-Series and Cross-Country Evidence. In World Bank Working Papers 904; World Bank Publications: Washington, DC, USA, 1992; Volume 23, p. 300. [CrossRef]

14. Grossman, G.M.; Krueger, A.B. Environmental Impacts of a North American Free Trade Agreement. In CEPR Discussion Papers; Centre for Economic Policy Research: London, UK, 1992; Volume 8, pp. 223-250. [CrossRef]

15. Odum, H.T. Ecological and General Systems; University Press of Colorado: Boulder, CO, USA, 2012.

16. Koohafkan, P.; Altieri, M.A.; Gimenez, E.H. Green agriculture: Foundations for biodiverse, resilient and productive agricultural systems. Int. J. Agric. Sustain. 2012, 10, 61-75. [CrossRef]

17. United Nations Department of Economic and Social Affairs. The 17 Sustainable Development Goals (SDGs) to Transform Our World. Available online: https:/ / www.un.org/development/desa/disabilities/envision2030.html (accessed on 6 November 2021).

18. Dima, O.; Inzé, D. The role of scientists in policy making for more sustainable agriculture. Curr. Biol. 2021, 31, R218-R220. [CrossRef] [PubMed]

19. Abubakar, M.S.; Attanda, M.L. The Concept Sustainable Agriculture: Challenges and Prospects. IOP Conf. Ser. Mater. Sci. Eng. 2013, 53, 012001. [CrossRef]

20. Nuthalapati, C.; Bathla, S.; Kumar, A.; Jha, G. Agriculture and sustainable development goals: An overview and issues. Agric. Econ. Res. Rev. 2018, 31, 1-7. [CrossRef]

21. Trigo, A.; Marta-Costa, A.; Fragoso, R. Principles of Sustainable Agriculture: Defining Standardized Reference Points. Sustainability 2021, 13, 4086. [CrossRef]

22. Liu, X.B.; Zhang, X.Y.; Wang, Y.X.; Sui, Y.Y.; Zhang, S.L.; Herbert, S.J.; Ding, G. Soil degradation: A problem threatening the sustainable development of agriculture in Northeast China. Plant. Soil Environ. 2010, 56, 87-97. [CrossRef]

23. Yevich, R.; Logan, J.A. An assessment of biofuel use and burning of agricultural waste in the developing world. Global. Biogeochem. Cycles 2003, 17, 1095. [CrossRef]

24. Szewrański, S.; Kazak, J.; Żmuda, R.; Wawer, R. Indicator-based assessment for soil resource management in the Wrocław Larger Urban Zone of Poland. Pol. J. Environ. Stud. 2017, 26, 2239-2248. [CrossRef]

25. Hundal, L.S. The conversion to sustainable agriculture. J. Environ. Qual. 2012, 41, 616. [CrossRef]

26. Pretty, J.; Hine, R. The promising spread of sustainable agriculture in Asia. Nat. Resour. Forum 2000, 24, 107-121. [CrossRef]

27. Forouzani, M.; Karami, E. Agricultural water poverty index and sustainability. Agron. Sustain. Dev. 2010, 31, 415-431. [CrossRef]

28. Cazorla, A.; de Los Ríos Carmenado, I. Working with People, M.M.S. (WWP) in Rural Development projects: A proposal from social learning. Cuad. Desarro. Rural. 2013, 10, 131-157. [CrossRef]

29. Zhao, Q.G.; Xu, M.J. Sustainable agriculture evaluation for red soil hill region of Southeast China. Pedosphere 2004, 14, 313-321. [CrossRef]

30. Jat, R.S.; Choudhary, R.L.; Singh, H.V.; Meena, M.K.; Singh, V.V.; Rai, P.K. Sustainability, productivity, profitability and soil health with conservation agriculture based sustainable intensification of oilseed brassica production system. Sci. Rep. 2021, 11, 13366. [CrossRef] [PubMed]

31. Chen, R.; Zhang, R.; Han, H. Climate neutral in agricultural production system: A regional case from China. Environ. Sci. Pollut. Res. 2021, 28, 33682-33697. [CrossRef] [PubMed]

32. Zhang, L.; Xu, X. Difference in carbon footprint between single- and double-cropping rice production in China, $2003-2016$. Environ. Sci. Pollut. Res. 2021, 28, 27308-27317. [CrossRef]

33. Wurster, P.; Maneta, M.; Beguería, S.; Cobourn, K.; Maxwell, B.; Silverman, N.; Ewing, S.; Jensco, K.; Gardner, P.; Kimball, J.; et al. Characterizing the impact of climatic and price anomalies on agrosystems in the northwest United States. Agric. Forest Meteorol. 2020, 280, 107778. [CrossRef]

34. Haqiqi, I.; Bahalou Horeh, M.B. Assessment of COVID-19 impacts on US counties using the immediate impact model of local agricultural production (IMLAP). Agric. Syst. 2021, 190, 103132. [CrossRef]

35. Su, Y.; He, S.; Wang, K.; Shahtahmassebi, A.R.; Zhang, L.; Zhang, J.; Zhang, M.; Gan, M. Quantifying the sustainability of three types of agricultural production in China: An energy analysis with the integration of environmental pollution. J. Clean. Prod. 2019, 252, 119650. [CrossRef] 
36. Li, C.; Jiang, T.T.; Luan, X.B.; Yin, Y.L.; Sun, S.K. Determinants of agricultural water demand in China. J. Clean. Prod. 2020, 288, 125508. [CrossRef]

37. Deng, L.; Chen, L.; Zhao, J.; Wang, R. Comparative analysis on environmental and economic performance of agricultural cooperatives and smallholder farmers: The case of grape production in Hebei, China. PLoS ONE 2021, 16, e0245981. [CrossRef] [PubMed]

38. Poveda, J. Insect frass in the development of sustainable agriculture. A review. Agron. Sustain. Dev. 2021, 41, 5. [CrossRef]

39. Durán, R.L.; Dong, S. Plant biotic interactions: From fundamental research toward sustainable agriculture. J. Integr. Plant. Biol. 2021, 63, 275-276. [CrossRef]

40. Lemaire, G.; Tang, L.; Bélanger, G.; Zhu, Y.; Jeuffroy, M.H. Forward new paradigms for crop mineral nutrition and fertilization towards sustainable agriculture. Eur. J. Agron. 2021, 125, 126248. [CrossRef]

41. Ashraf, S.A.; Siddiqui, A.J.; Elkhalifa, A.E.O.; Khan, M.I.; Patel, M.; Alreshidi, M.; Moin, A.; Singh, R.; Snoussi, M.; Adnan, M. Innovations in nanoscience for the sustainable development of food and agriculture with implications on health and environment. Sci. Total Environ. 2021, 768, 144990. [CrossRef]

42. Zhou, W.B.; Duan, F.Y. Closing crop yield and efficiency gaps for food security and sustainable agriculture. J. Integr. Agric. 2021, 20, 343-348. [CrossRef]

43. Mouratiadou, I.; Latka, C.; van der Hilst, F.; Müller, C.; Berges, R.; Bodirsky, B.L.; Ewert, F.; Faye, B.; Heckelei, T.; Hoffmann, M.; et al. Quantifying sustainable intensification of agriculture: The contribution of metrics and modelling. Ecol. Indic. 2021, 129, 107870. [CrossRef]

44. Wings, T.K.; Spielmeyer, A.; Glaeser, S.P.; Schauss, T.; Hamscher, G.; Kämpfer, P.; Dott, W. Prevention of human health risks and environmental pollution from agricultural waste. Toxicol. Lett. 2014, 229, S131. [CrossRef]

45. Zhang, M.; Cui, W.K.; Zhang, Y.J.; Xu, Y.H. Research on world food production efficiency and environmental sustainability based on entropy-DEA model. Complexity 2021, 2021, 8730264. [CrossRef]

46. Liu, C.; Chen, J.; Cai, W. Data-driven remanufacturability evaluation method of waste parts. IEEE Trans. Ind. Inform. 2021. [CrossRef]

47. Liu, C.; Gao, M.; Zhu, G.; Zhang, C.; Zhang, P.; Chen, J.; Cai, W. Data driven eco-efficiency evaluation and optimization in industrial production. Energy 2021, 224, 120170. [CrossRef]

48. Li, D.; Nanseki, T.; Takeuchi, S. Measurement of agricultural production efficiency and the determinants in China based on a DEA approach: A case study of 99 farms from Hebei province. J. Fac. Agric. Kyushu Univ. 2012, 57, 235-244. [CrossRef]

49. Sun, B.; Yang, X.; Zhang, Y.; Chen, X. Evaluation of water use efficiency of 31 provinces and municipalities in China using multi-level entropy weight method synthesized indexes and data envelopment analysis. Sustainability 2019, 11, 4556. [CrossRef]

50. Charnes, A.; Cooper, W.W.; Rhodes, E. Measuring the efficiency of decision making units. Eur. J. Oper. Res. 1978, 2, 429-444. [CrossRef]

51. Banker, R.D.; Charnes, A.; Cooper, W.W. Some Models for Estimating Technical and Scale Inefficiencies in Data Envelopment Analysis. Manag. Sci. 1984, 30, 1078-1092. [CrossRef]

52. Vlontzos, G.; Niavis, S.; Manos, B. A DEA approach for estimating the agricultural energy and environmental efficiency of EU countries. Renew. Sustain. Energy Rev. 2014, 40, 91-96. [CrossRef]

53. Li, J.; Chen, J.; Liu, H. Sustainable agricultural total factor productivity and its spatial relationship with urbanization in China. Sustainability 2021, 13, 6773. [CrossRef]

54. Darmody, R.G.; Jansen, I.J.; Carmer, S.G.; Steiner, J.S. Agricultural impacts of coal mine subsidence: Effects on corn yields. J. Environ. Qual. 1989, 18, 265-267. [CrossRef]

55. Ikkala, L.; Ronkanen, A.K.; Utriainen, O.; Klve, B.; Marttila, H. Peatland subsidence enhances cultivated lowland flood risk. Soil Tillage Res. 2021, 212, 105078. [CrossRef] 